\title{
How Women's Silence Secures The Peace: Analysing Sexual And Gender-Based Violence In A Low Intensity Conflict
}

\author{
Sara E. Davies (Griffith University), Jacqui True (Monash University) and \\ Maria Tanyag (Monash University)
}

Key words: peace process, Mindanao, clan violence, sexual violence, gender

\section{NB: all citations of personal interviews can go in footnotes but we have left them in the text for now}

\begin{abstract}
There is a growing body of literature on the gendered impacts of conflict and the disproportionate vulnerability of women and girls, in particular, to sexual and genderbased violence (SGBV) during conflict. Most studies focus on SGBV atrocities committed in highintensity conflict environments. Comparatively few studies analyse the patterns of SGBV in protracted low-intensity conflict and fragile state environments. These environments are characterised by intermittent, often localised fighting and constant renewal of ceasefire processes while protracted disagreements between the warring parties remain. Civilian populations, particularly internally displaced persons, are disproportionately vulnerable to targeted sexual and gender-based violence (SGBV). In such contexts there are typically limited opportunities for victims to report violence or to receive protection. We examine the current Mindanao Peace Process in the Philippines to highlight the disempowerment of survivors of SGBV due in large part to the reporting constraints that affect those most likely to be targeted for sexual violence by rival groups, some of whom are closely associated with the Peace Process. By making visible the significant social, political-economic, and institutional barriers affecting the recognition and reporting of sexual and gender-based violence, we discuss how and why conflict-related SGBV continues in fragile and low intensity conflict environments.
\end{abstract}




\section{Introduction:}

The Asia Pacific region has been relatively neglected in recent reports on the gender-specific impacts of conflict, including those on the disproportionate vulnerability of women and girls to sexual and gender-based violence (SGBV) during and after war or conflict. ${ }^{1}$ This research neglect coincides with the broad decline in deaths from major conflicts in Asia and the Pacific in recent decades (Aspinall et al 2012). However, it would be false to assume that widespread and systematic sexual and gender-based violence (SGBV) is absent in the region due to this decline and the prevalence of low intensity conflicts rather than major civil or interstate war (cf. True 2015). To the contrary, we argue that fragile and low intensity conflict situations have political and structural conditions such as impunity and weak law enforcement, proliferation of small arms, economic hardship, poor state services and gender hierarchies that can lead to the perpetration of mass atrocities, especially SGBV. Moreover, we contend that the intense political machinations during conflicts and peace processes often both create and reinforce the silence surrounding SGBV crimes and their non-reporting, particularly for the most vulnerable groups of women and girls targeted for this form of violence.

In Asia Pacific, multiple conflicts fan out from clan/kinship and intra-community levels to civil war with rebel groups fighting against the state. These localised conflicts exacerbate gender and other material inequalities and grievances. They make sexual and gender-based violence an effective form of political (and economic) violence to instil fear and repression in communities. This is because the pervasive shame and stigma attached to the survivors (and their families) of SGBV and the frequently insurmountable institutional and political barriers to SGBV reporting, preserve the culture of impunity for these crimes. Internally displaced persons (IDPs), and women and girls from minority ethnic, religious and indigenous groups are most vulnerable to conflict-related SGBV. These groups are largely disenfranchised from the right and the opportunity to report human rights violations due to poor infrastructure and services in the conflict-affected areas in which they live as well as systemic gender discrimination and inequalities. Structural conditions, above all, rather than any inherent vulnerability attached to particular bodies, makes marginalised, minority women and girls primary targets for SGBV.

To explore these arguments we examine the dynamics of conflict and peace in one case of a fragile and low intensity conflict-affected area, Mindanao, the Philippines. Like several other contexts in the Asia, Mindanao is a fragile area marked by the presence of protracted conflicts that stretch back to independence of the Philippines. However, the region is unique in that it has also engendered a peace process in which women's participation has been highlighted internationally as playing a crucial part. Investigating the Mindanao case, we critically analyse the sources of knowledge informing both researchers' and policymakers' understanding of conflict-related sexual and gender-based violence (SGBV). We examine existing data on SGBV reports and relevant informal knowledge and contextualisation about who is committing SGBV, who are the targets of SGBV, and whose voices therefore need to be represented in peace processes to prevent this violence. 


\section{The Case of Mindanao}

The Philippines is recognised as a 'success story' or a model for women's participation in peace (UN Women 2015). The Bangsamoro peace process, which refers to the peace process between the Government of the Philippines and the Moro Islamic Liberation Front (MILF), is considered a trailblazer for its inclusion of civil-society representatives in contrast to peace processes involving only military representatives of armed parties. Women were present from both sides of the peace table and throughout the negotiation process. ${ }^{2}$ The government also appointed a woman, Miriam Coronel-Ferrer, as chief negotiator and signatory of the peace deal representing a world-first in historically male-dominated peace processes. In the Asia Pacific region, the Philippines is also considered a leader in the localisation of the Women, Peace and Security agenda, being the first country in the region to develop a National Action Plan (NAP) for the implementation of UN Security Council Resolution 1325. As part of that NAP and also the government's commitment under the UN CEDAW, the Philippines National Commission on Women collects statistics on police reports of 13 different types of violence against women and girls across 18 different regions and areas nationwide.

\section{Insert Table 1 here.}

Sources: The Philippines National Commission on Women; Republic of the Philippines National Police Commission.

In table 1 we see the variation across regions with the lowest number of reports and those with the highest recorded in 2014 and 2015. Strikingly, the conflict-affected Autonomous Region of Muslim Mindanao (ARMM) with a population of 2.41 million shows the lowest number of VAW cases of any region in the Philippines with just 152 cases reported in 2015 (152 cases in 2014). Showing a similar pattern, ARMM also reported the lowest overall crime rates in the Philippines in 2014 (Vargas 2014). However, Davao, the largest urban centre in Mindanao with a Christian majority population of 868,690 , recorded the highest number of VAW cases in the Philippines with 7166 reports in 2015, representing 17.3 per cent of nationwide reports in 2015 (7825 in 2014). This is a very high number relative to the population of Davao suggesting a pattern of higher VAW reports in conflict-affected contexts where there are lesser - systemic gender discrimination and institutional - barriers to reporting. Western Visayas with a population of 6,211,038 recorded the second highest number of VAW cases from January to December 2015 with 6660 reported cases, andthe highest prevalence among all regions with 7925 cases in 2014. That region constitutes several provinces that have experienced the devastating effects of Typhoon Haiyan on November 8, 2013 including the displacement of many people in the aftermath and the presence of international humanitarian and aid agencies. In correlation, it accounted for 16.9 per cent of VAW nationwide reports in 2014.

Our knowledge of violence against women and girls, and conflict-related sexual and genderbased violence (SGBV) in particular, is limited if we only take into consideration the national figures on official reports. For instance, data showing that the ARMM region has the lowest number of reports of any region, is at odds with the much high reporting in the neighbouring, urban and predominantly Christian region of Davao (see Table 1). This strongly suggests that there is a relationship we must interrogate between non-reporting of VAW and systemic gender discrimination exacerbated by particular conflict dynamics. Despite women's participation in the Mindanao peace process, SGBV in Mindanao remains under-reported, under-examined, and unaddressed. The prevalence of SGBV directed at women and girls belonging to minority groups and internally displaced in Mindanao has not been discussed in the context of any formal peace process. We argue that there are three reasons for this neglect. 
First, the peace process is focused on conflict-resolution between the Government and one major armed group, the MILF, in Mindanao (Franco 2016). However, there are multiple actors involved in conflict in Mindanao including numerous armed groups but also clans, criminal gangs and political elites (see Dwyer and Cagoco-Guiam 2012: 23). Violence is highly localised and though SGBV may not be an explicit strategy among the major armed groups, sexual crimes in the context of clan retaliation ('rido') frequently morphs into other forms of conflict involving major armed groups. Failure to recognise the complex conflict dynamics and range of actors in Mindanao can lead to the assumption that SGBV does not exist in this particular fragile, conflictaffected setting.

Second, related to the neglect of the multiple conflicts in Mindanao, the recording of conflictrelated violence as "battle deaths over the threshold of 1000 deaths" excludes many deaths resulting from localised and protracted conflicts, as well as other forms of violence, such as SGBV, that represent significant violations of human rights. Deaths from clan violence, for instance, represent the highest proportion of 'battle deaths' in Mindanao, though in any given year they may not be counted. However, as we show, identifying the location of clan violence will often also identify situations of SGBV.

Third, the disempowerment of SGBV survivors in being able to report the violence they have experienced as a result of marginalisation and displacement means that we cannot know the full extent of the problem of SGBV. It is crucial that we do not interpret the non-reporting of SGBV violations or silence as the absence of SGBV given the material, institutional and gendered constraints on reporting for the most vulnerable groups. The invisibility of conflict-related SGBV in Mindanao and in Asia Pacific more generally is affected by the political conditions that define how conflicts are understood, which forms of violence are recognised, and whose voices are accounted for. In the remainder of the article, we explore these issues focusing particularly on the structural and institutional conditions that prevent SGBV survivors from reporting violence and participating in peace processes.

\section{Whose conflict and whose counting?}

How conflicts are understood and measured affects our ability to observe the presence of sexual and gender-based violence (SGBV) and interpret how widespread and systematic it is within fragile and conflict-affected settings (Swaine 2015). Mindanao is the site for the majority of armed and violent conflicts in the Philippines but traditional measures for counting whether a situation is a 'conflict' requires a violence 'threshold' to be met between two or more warring parties. Despite the multiple actors and types of conflict in Mindanao (see Table 2) most accounts of armed conflict focus solely on the intra-state conflict between Muslim or 'Moro' rebels and the Philippine government armed forces. The intra-Moro insurgencies in the region are not considered to be the main source of conflict in the region by INGOs and academics working in the ARMM. Thus, while resolving the conflict between the GPH and the MILF will be a step towards peace in the ARMM, it will not end the multiplicity of conflicts in the region. Rido or clan feuding will remain one of the primary drivers of conflict in the region and conflict actors in the ARMM.

\section{Insert Table 2 here}

The major database for recording past and ongoing conflicts is the Uppsala Conflict Data Program (UCDP). ${ }^{3}$ UCDP is updated annually and includes different forms of conflict involving intra-state, non-state as well as one-sided violence against civilians. However, it only records ongoing conflicts in the Philippines with battle deaths over 1000 per annum. One-sided violence, such as clan conflict at the local level, falls out of this categorisation because it only accounts for a small number of deaths. However, political violence remains. Now it is between 
and among clans, tribes and local elites, rather than insurgency-related conflict. This is now the dominant form of violent conflict in ARMM (International Alert 2014: 2) with disputes over illicit trade in arms and arm production. As Rood (2005: 6) explains, "what begins as a dispute between families can end with organised armed forces clashing, as parties to the dispute persuade others to become involved or the Philippine military can mistake a clan clash as a separatist operation and intervene on its own."

An initiative led by International Alert and the World Bank provides quantitative data that illustrates the main drivers of conflict in the Autonomous Region of Muslim Mindanao (ARMM), disaggregated by province. This is called the Bangsamoro Conflict Monitoring System. The BCMS uses the concept of violent conflict, which refers to "incidents where two or more parties use violence to settle misunderstandings and grievances, and/or defend and expand their individual or collective interests (e.g. social, economic, political resources and power, etc.)." Incidents of these conflicts are gathered from two key data sources: police databases and credible media sources. BCMS findings suggest that violence in Mindanao, particularly in the volatile provinces of ARMM, ranges from clan feuds to non-state armed conflict, and intra-state conflict (BCMS 2014: 28). ${ }^{4}$ Indeed, the BCMS (2014) shows how the majority of violent conflicts in Mindanao emanate from clan and tribal dynamics in the region. Clan feud or 'rido' as it is termed in Moro culture is typical of "small-scale societies where family and kinship ties are the main sources of authority and where there is a lack of effective state control and authority" (Torres III 2014: 8).

From the 1930s to 2005, there was a total of 1,266 documented cases of rido, accounting for approximately 5,500 deaths, 64 per cent of which remain unresolved (Torres III 2014). Approximately half of this total of rido incidents recorded by BCMS occurred in the last five years (2000-2004), averaging around 127 new cases per year. This violence is rarely reported in and by national and international sources. For example, compared to the recorded cases of rido-related violence, local estimates for which are in the hundreds (International Alert 2014), UCDP recorded just two rido incidents from 1998 to present.

One significant problem with the focus on the numbers of deaths as the criterion for defining a situation as conflict is that the type of conflict and conflict dynamic(s) affecting most people's lives is attached to recognition of the situation as having conflict-related SGBV cases. That is, when conflict drops out of focus so does SGBV (Swaine 2015). It is no coincidence that in the four years that the UN Secretary-General has provided annual reports on sexual violence in conflict-affected situations, the Philippines - Mindanao specifically - has never been mentioned (see n.1; Ban 2015).

Clan violence dominates the interpersonal and intra-community realm and it is closely connected to the occurrence of sexual and gender-based violence (SGBV) amongst clans (Hilsdon 2009). It is important to note that women are not equally vulnerable to this systematic SGBV and this may explain the volume of silence concerning the extent of SGBV in Mindanao. Rape and sexual violence are commonly perpetrated by elite clans and their private armies (Personal Interview with female, Mindanao-based peace worker,Philippines, 16 March 2015). Women belonging to elite clans are at a gross advantage while poor women in rival clans or indigenous communities are the easy targets because they and their families are powerless against the violence (Personal Interview with female, Mindanao-based NGO and community leader, Philippines, 18 March 2015). Clan feuds can be triggered by land disputes and political rivalries, but the use of sexual violence to settle these disputes originates in the practice of using sexual violence against women to defend group boundaries (Hilsdon 2009). There is a practice, 'guyod' ${ }^{1}$, where women and girls are abducted by clan members and then forced into marriage. Women are deliberately raped to coerce the families to consent to marry her off because they

\footnotetext{
${ }^{1}$ Guyod is a Visayan word which means to forcefully pull or drag to the ground. For females, this occurs through dragging by the hair.
} 
know after rape she will be considered damaged property to the family and clan honour (Personal Interview with female, international development organisation, Philippines, 10 March 2015). Consequently, we found in interviews that forced marriage is the outcome of sexual and gender-based violence often tied to clan conflict dynamics. In Sulu, for example, young girls are abducted, raped and then forced into marriage by armed clan groups, in that order (Personal Interview with female, Mindanao-based peace worker, Philippines, 16 March 2015). One informant in Mindanao discussed how daughters are offered for marriage to appease warring clans though even the sacrifice of daughters may not be able to prevent future clan violence from re-igniting (Personal Interview with female, Mindanao gender consultant and academic, Philippines, 3 February 2015). Thus, demonstrating the fragility of peace forged at the expense of women and girls. Similarly, the targeting of women for rape as part of rido has been documented (see Torres III 2014). SGBV has also been strategically used by rival clans to gain and establish control over natural resources in mineral-rich areas (OHCHR 2015).

The perpetration of SGBV can intensify at moments of political contestations and rivalries during elections for political office in Mindanao and clans have vested interests in perpetuating the invisibility of this violence. A recent incidence of election-related violence is the infamous Maguindanao massacre perpetrated by the Ampatuan clan, which resulted in 57 deaths in 2009 . As Human Rights Watch (2010:6) argued, "the Maguindanao massacre was an aberration only because of how many people died [in one incident], not because of its cold-blooded brutality, which the government, military, and police has long tolerated, and even fuelled". Male members of the Ampatuan clan had committed hundreds of human rights violations, including sexual violence against poor and indigenous women and young girls, with routine impunity before the 2009 Maguindanao massacre reached national and international attention (Lingao 2013). Human Rights Watch's (2010) concern was that this massacre had been committed by a clan with a record of unchecked killings and other serious abuses perpetrated in Mindanao. They observed that Ampatuan clan members' propensity to kill female victims after raping them added to the unresolved cases of forced disappearances. Unreported SGBV in connection with extrajudicial killings by armed non-state actors and government forces, who have sometimes engaged clans such as Ampatuans as their de facto army, has crucial implications for an already fragile peace process on fragile populations.

As long as powerful clans in Mindanao remain invisible within the national peace and conflict negotiations, the SGBV crimes they commit are excluded and also not recognised as conflictrelated. The invisibility of rido-related sexual and gender-based violence creates a fragile environment that affects women and girls' ability to report the crimes and undermines possibilities for meaningful, gender-inclusive participation in peace.

\section{Whose experiences of violence?}

Silence about SGBV in conflict-affected situations does not mean there is an absence of this violence or that it is not widespread and systematic. Paradoxically, one of the starkest indications that SGBV is widespread is the presence of gender norms that prohibit or constrain reporting (Davies and True 2015). In the Mindanao case, there are three major structural, gender-based constraints that affect the ability of vulnerable groups to report incidents of sexual and gender-based violence: triggering new and/or intensifying existing clan-based violence as a result of reporting SGBV, lack of adequate and appropriate justice mechanisms to respond to SGBV survivors, and high volume of fragile displaced populations. We need to understand the specific political and practical challenges to reporting SGBV crimes for different groups given the insecurities engendered in the Mindanao context through multiple, overlapping forms of conflict. These challenges compromise all sources of information from international treaty-monitoring bodies, to national police reports and media stories. 
The first major barrier to reporting SGBV concerns the social marginalisation and stigma that is ascribed to victims especially women and girls as a result of culturally specific, gender-based codes of honour and pride within families and communities. Because of the shame associated with rape and other sexual violence, including trafficking, there is strong pressure for women and girls to keep the violence they have experienced to themselves in order to prevent family and community level violence, namely the escalation of clan violence (rido) (Personal Interviews, Mindanao, 2 February 2015, 18 February 2015, 25 February 2015, 4 March 2015, 13 March 2015). One informant stated that, "rape is very taboo in Mindanao. There is no reporting or complaints and even if there are legal remedies in place victims just disappear..." (Personal Interview with male, country representative for international organisation, Philippines, 4 March 2015). Given women's role as carriers of tradition with their bodies serving as visible markers of group identity and difference, silence is one way Muslim Moro and Lumad indigenous women can protect clan or kin pride and identity, from which their own status and dignity derives. In effect, as one informant told us, "they internalise the violence to reduce further and broader conflict" (Personal Interview with male, government official,_Philippines, 13 March 2015).

A second major challenge to reporting SGBV in Mindanao is the lack of access to effective institutional legal or justice mechanisms to actually report for women and girls belonging to low socio-economic status groups who are the disproportionate targets of this violence. Many barangays (villages) lack police stations and health centres where survivors could report the crime they have experienced and/or receive assistance. Barangay officials are often not trained or capable of issuing protection orders (Personal Interview with female, NGO leader and lawyer at a city protection unit, Philippines, 15 April 2016). Women as well as men commonly, carry guns for protection. Tellingly, one informant shared a joke that "women in Mindanao love their husbands less than they love their guns" (Personal Interview with female, representative of an NGO network, Philippines, 18 February 2015). A major organisation working in the region stressed that the more secluded and rural an area or locality, given the absence of state institutions, the more likely that extreme violence takes place and "the more room for silence and fear" (Personal Interview with male, NGO representative, Philippines, 25 March 2015). Conflict situations are also by nature fragile and unstable so regular reporting and monitoring systems are frequently disrupted. Even when there are national and international organisations present and cases are reported they may not surface at higher levels of policy-making because professional reputations are at stake and there is a lack of institutional transparency. For example, one informant told us that many officials are careful about the ramifications of high or low levels of reported cases: "If the reports are too high, then the government looks bad and a failure, but then if it is too low, the administration risks not receiving financial support and attention from external funding agencies" (Personal Interview with male, country representative for international organisation, Philippines, 4 March 2015). In addition, as our interviews corroborated in Mindanao, there are also the practical disincentives to report SGBV suffered by, mainly, female survivors whose dignity is at stake if badly treated - a universal problem in gender insensitive institutions.

For Muslim and indigenous women, their experiences of violence are further complicated by the presence of plural legal systems in Mindanao. Shari'a Law applies for personal and family relations among Muslims, while many Islamised indigenous groups also subscribe to customary laws concerning dispute settlements (Solamo-Antonio 2015). Grievances including those relating to SGBV are redressed in such a way that further harms women and girls, such as through forced marriage (including dowry); payment of 'blood money' as 'reparations'; and other arrangements which mean survivors continue to interact with perpetrators in their daily lives. A high-ranking police official in ARMM commented that they "found out that because of culture, people will not report [crimes] to the police, they consult their village chiefs because once they report it to the police, it is tantamount to a declaration of war" (quoted in Vargas 2014). 
Adding to these significant institutional constraints, situations of displacement present a third major challenge affecting the reporting of SGBV. Internal displacement due to conflict and seasonal natural disasters affecting Mindanao compounds the marginalisation of ethnic minorities and their difficulties in accessing public infrastructures and humanitarian assistance to report and address SGBV. According to the Internal Displacement Monitoring Centre (IDMC), in 2014 nearly half a million people were displaced in Mindanao. Within that figure 123800 people were displaced due to armed conflict, crime and clan-based violence; the remainder were displaced, primarily, due to natural disasters (typhoons and storms) (IDMC 2015). Nearly all of those who remain displaced in Mindanao belong to Muslim ethnic minorities and are amongst the poorest and most vulnerable IDPs. The majority have no formal land ownership or tenancy rights in their areas of origin (Kok 2015). Displacement tends to be 'semi-permanent' with many people trapped in long and protracted evacuation due to conflict, where families return to their homes, only to be once again displaced by new clashes (IDMC 2015). In this prolonged state of displacement in camps with poor health, water and sanitation facilities, IDPs are exposed to abuse, exploitation, disease and death (Kok 2015). In one Mindanao displacement context, Zamboanga, 7,335 people remain displaced in evacuation camps and 12, 576 people in transition sites (UN OCHA 2015). When disasters such as drought and flooding occur in conflict situations, they compound the problem of protracted displacement and create new protection gaps for communities (IDMC 2015). One organisation we interviewed which provided assistance for IDPs camps in Mindanao admitted that their referral system failed to protect women and girls due to being overwhelmed by continued crisis situation(s) (Personal Interview with female, international development organisation, Philippines,, 10 March 2015).

Indigenous women and girls are specifically targeted for SGBV because they are among the most powerless and neglected group in the region. The exclusion of the Lumad indigenous group from the peace process is compounded by their particular vulnerability to displacement due to loss of land for Moro populations, military operations, mining and logging projects. Lumads have clear barriers to accessing barangay and other state mechanisms for reporting due to their geographical isolation. Many Lumads are not even registered in national census. In such a situation crimes against Lumads become 'everyday' occurrences (Ferrie 2016).

This has obvious impact with respect to the recording of SGBV reports against indigenous peoples. As shown in Table 1, this region has remarkably low volume of VAW reports, let alone SGBV, in comparison to its surrounding areas. In short, the lack of protection experienced by minority women and girls in conflict-affected Mindanao affects their ability to report violence, this personal fear as indigenous women is amplified in an environment where violent retribution and poor institutional resources already constrain reporting practices. Therefore referring to the absence of reports as evidence of the absence of the problem distorts our understanding and analysis of the patterns of SGBV. Tragically the peace process, at this stage, does not address the conditions that have led to SGBV to continue with near impunity: fear of clan violence if women report, the lack of institutions that women trust to report to, and the protracted displacement of particular disenfranchised groups, i.e. Lumad, appears likely to continue.

\section{Whose voices?}

Given the reality of fragile contexts such as Mindanao where severely limited opportunities to report SGBV exacerbate a culture of silence and impunity for this violence, what can we expect gender inclusion in the peace processes to look like? The Bangsamoro peace process in Mindanao is relatively inclusive compared to previous negotiations yet it is still characterised by limited representation and participation of diverse groups (displaced and Lumad populations) affected by conflict, particularly marginalised women. The selection of individual women for a seat at the peace table has been largely tied to their dominant ethnic and religious status. The barriers to preventing SGBV crimes aimed at Lumad and IDP women and girls, for 
instance, are also barriers to their participation in peace. The long-term effects of displacement on these women's well-being and socio-economic opportunities disadvantages them in any present political process.

Inclusiveness with respect to gender means being sensitive to the multiple subjectivities of women, their roles, and how gendered social relations affect women's capacities to participate and be included in the governance of peace and security. The influence that women as a group can have in representing women's interests in a peace process is less a feature of their numbers or their elite presence at the peace table than the concrete and fundamental reforms they collectively push for (Paffenholz et al 2016). One of the fundamental reforms that is in women's interests to push for is the public recognition of SGBV in this fragile setting, and the end of impunity for this violence, which means access to justice, protection, and redress for SGBV survivors. Jenkins and Goetz (2010), however, find that even where local women are present at peace talks, raising issues of ongoing sexual or gender-based violence can be difficult. Moreover, it is particularly difficult in an environment where the violence being 'counted' and the people being subjected to this violence are not included in the peace process, as is the case for the populations most at risk of SGBV in Mindanao.

In fragile contexts such as Mindanao how can the safety of women most affected by SGBV be ensured to enable them to report and voice their concerns in the peace process? The short-term approach to humanitarian assistance while offering one of the very few sources of protection for marginalised women and girls also represents a major challenge for ongoing protection. Humanitarian agencies are typically funded only to address SGBV in the context of a crisis defined according to a particular threshold of conflict or disaster. These agencies are under pressure to respond only to the crisis situation and not to provide long-term protection, peacebuilding and equality measures (GenCap 2015).

In situations where the reporting of SGBV is too difficult and dangerous, how can we ensure the participation of IDP and indigenous women in peace processes without placing them in the dangerous position that they fear? This form of gender-inclusive participation is crucial for gender-inclusive protection because marginalised women of minority status often remain in the same violent, social conditions that caused their displacement and marginalisation in the first place.

\section{Conclusion}

Researchers and policymakers who hold that women's presence in peace processes can improve outcomes, highlight that in the Mindanao context women have served as mediators between feuding clans because they are rarely targeted in clan disputes and revenge killings. They argue that because women's physical security is less threatened than men's, this enables them to facilitate peace by means of collecting retribution payments and hosting reconciliation feasts (O'Reilly et al 2015: 20). Yet our analysis shows how clan membership fuels conflict at communal and intra-state levels, and how the clan concept of 'revenge' or 'rido' disproportionately accounts for sexual and gender-based violence perpetrated against marginalised, minority women and girls.

In Mindanao, where the state is either weak or absent, women who belong to powerful families have access to significant protection provided by armed male members of families with superior weapons and often their own private armies. This fact may improve their individual position to champion women's participation in the peace process, but this is not the same as championing women's issues and rights affected by the conflict. Moreover, while clan membership and/or kinship facilitates some women's participation in communal and intra-state peace negotiations, it is also through clans that women and girls with lower social, political and economic status are systematically targeted for SGBV as part of the political dynamics of inter-clan conflicts. Women 
of low status are not outside of conflict but their voices may not be represented among the parties to peace agreements.

The Mindanao case illustrates how women in conflict situations may be forced into silence about the abuses they suffer as a result of the material, institutional and social barriers in their everyday contexts to reporting experiences of SGBV and to participating in peace processes. The fragility of the peace process lies not only in the agreement itself but also in the selectivity of who contributes to, and benefits from, the peace process. For Lumad women, as well as longterm displaced women and girls, the conflict is experienced as silent survival. Their bodies are part of clan feuds that they cannot speak out against for fear of more rido attacks; their reluctance to report sexual attacks, coupled with the cultural inhibitions around reporting such violence, prevents adequate responses by the law and justice system; and their marginalisation and invisibility as participants in peace and security entrenches their ongoing vulnerability to attack.

Women's silence may secure the peace, but peace is fragile and unlikely to be sustainable under these conditions. The failure to acknowledge clan and community levels of violence as unrelated to national discussions of peace and security results from the privileging of intra-state conflicts and of the counting of battle deaths. It also has flow on effect to locating SGBV violations. In particular, failure to look for SGBV in low intensity conflict situations sustains both its invisibility and its effectiveness at excluding particular populations from their political and civil rights. The Mindanao case reveals, however, that without recognition of the problem of SGBV, we cannot expect improvements in protection, participation, or the prevention of violence and conflict in this fragile environment where there remain high numbers of displaced and disenfranchised populations.

Women's participation has been celebrated as instrumental in resolving the protracted conflict in Mindanao. However, there has not been only one conflict to end in Mindanao. Failure to recognise the multiple armed conflicts at the communal level, however, poses a significant barrier to raising and addressing the problem of sexual and gender-based violence that continues to target women from unrepresented minority groups in the peace process. The conflict-affected situations in the Asia Pacific region are complex in that their low intensity of deaths per year cover up the multitude of repressive forms of violence that still subjugate populations. In particular, the low intensity conflict designation makes mapping the patterns of sexual violence a difficult but vital task to illustrate the relationship between gendered political violence and political violence. Only by addressing this relationship can we identify appropriate strategies to ensure the inclusion of those groups being systematically targeted for such violence, which will mitigate their ongoing vulnerability and prevent future conflict and violence. 


\section{References}

Aspinall, Edward, Robin Jeffry and Anthony Regan eds. 2012. Diminishing Conflicts in Asia and the Pacific: Why Some Subside and Others Don't. New York: Routledge.

Ban, Ki-Moon. 2015. Conflict-Related Sexual Violence. Report of the Secretary-General. UN Security Council, 23 March. S/2015/203,

Davies, Sara E. and Jacqui True. 2015 "Reframing Conflict-Related Sexual and GenderBased Violence: Bringing Gender Analysis Back In." Security Dialogue 46, 6: 495-512.

Dwyer, Leslie and Rufa Cagoco-Guiam. 2012. Gender and Conflict in Mindanao. The Asia Foundation.

Ferrie, Jared. 2016. "Caught in the Crossfire”, IRIN Humanitarian News, 28 April. https://www.irinnews.org/feature/2016/04/28/caught-crossfire

Franco, Joseph. 2016. "Whether Fact or Fiction, ISIS Claims Threaten Philippines Peace”, The Global Observatory, International Peace Institute. 15 April.

https://theglobalobservatory.org/2016/04/isis-philippines-abu-sayyaf-mindanao/

Hilsdon, Anne-Marie. 2009. "Invisible Bodies: Gender, Conflict and Peace in Mindanao." Asian Studies Review 33, no. 3: 349-365.

Human Rights Watch. 2010. "They Own the People": The Ampatuans, State-backed Militias, and Killings in the Southern Philippines. November. New York: Human Rights Watch.

International Alert. 2014. Rebellion, Political Violence and Shadow Crimes in the Bangsamoro: The Bangsamoro Conflict Monitoring System (BCMS), 2011-2013. August. http://www.international-alert.org/resources/publications/rebellion-politicalviolence-and-shadow-crimes-bangsamoro

Internal Displacement Monitoring Centre (IDMC). 2015. Philippines: long-term recovery challenges remain in the wake of massive displacement, 10 February. http://www.internal-displacement.org/south-and-south-eastasia/philippines/2015/philippines-long-term-recovery-challenges-remain-in-the-wakeof-massive-displacement

Jenkins, Robert \& Anne-Marie Goetz. 2010. "Addressing sexual violence in internationally mediated peace negotiations.” International Peacekeeping, 17 no.2: 261-77.

Kok, Frederik. 2015. "Philippines: Why housing rights must be prioritised to end displacement of Zamboanga's urban poor.” IDMC Briefing Paper, January 15.

Lingao, Ed. 2013. "The Clan Politics of ARMM: Ampatuans, web of kin warp Maguindanao polls." The Maguindanao Chronicles: Philippine Center for Investigative Journalism. April 10. http://pcij.org/stories/ampatuans-web-of-kin-warp-maguindanao-polls/.

O’Reilly, Marie, Andrea Suilleabhain, and Thania Paffenholz. 2015. Reimagining Peacemaking: Women's Roles in Peace Processes. International Peace Institute. https://www.ipinst.org/2015/06/reimagining-peacemaking-womens-roles-in-peaceprocesses

Paffenholz, Thania, Nick Ross, Steven Dixon, Anna-Lena Schluchter, and Jacqui True. 2016. Making Women Count - Not Just Counting Women: Assessing Women's Inclusion and Influence on Peace Negotiations. Geneva and New York: Inclusive Peace and Transition Initiative and UN Women.

Rood, Steven. 2005. "Forging Sustainable Peace in Mindanao: The Role of Civil Society." Policy Studies 17. Washington: East-West Center Washington.

Solamo-Antonio, Isabelita. 2015. "The Philippine Shari'a Courts and the Code of Muslim Personal Laws." In The Sociology of Shari'a Case Studies from around the World, eds. A. Possamai et al., pp. 83-101. Cham: Springer.

Swaine, Aisling. 2015. "Beyond Strategic Rape and Between the Public and Private: Violence Against Women in Armed Conflict". Human Rights Quarterly 37, no.3, 755-786

Torres, Wilfredo M. III. Ed. 2014. Rido: Clan feuding and conflict management in Mindanao, expanded edition. Manila: Asia Foundation and Ateneo de Manila University Press.

True, J. 2015. "'Winning the Battle but Losing the War: A Feminist Perspective on the Declining Global Violence Thesis." International Feminist Journal of Politics 18, 4.

UN Office for the Coordination of Humanitarian Affairs (OCHA). 2015. Zamboanga 
Humanitarian Snapshot. January 30.

UN Office for the High Commissioner on Human Rights (OHCHR). 2015. "Statement of the United Nations Special Rapporteur on the human rights of internally displaced persons, Chaloka Beyani, on the conclusion of his official visit to the Philippines, 21 to 31 July 2015." 31 July. http://www.ohchr.org/en/NewsEvents/Pages/DisplayNews.aspx?NewsID=16280\&Lan gID=E (accessed 7 January 2016).

UN Women. 2015. Preventing Conflict, Transforming Justice, Securing the Peace: A Global Study on the Implementation of United Nations Security Council 1325.

Vargas, Anthony. 2014. "ARMM is most peaceful Philippine region - PNP." The Manila Times, January 25.

\footnotetext{
${ }^{1}$ For example: the annual UN Secretary-General reports on sexual violence in conflict-affected situations has listed four countries from Asia (Afghanistan, Cambodia, Myanmar and Sri Lanka) over the 4 years of reporting (2012-2015), see http://www.un.org/sexualviolenceinconflict/key-documents/reports/ (30 April 2016); and the Office of the Special Representative of Secretary-General for Sexual Violence in Conflict does not have one country from Asia listed amongst its 11 'case' countries, see http://www.un.org/sexualviolenceinconflict/ (30 April 2016).

${ }^{2}$ Women comprised 50 per cent of the government's negotiating team and 25 per cent of the signatories.

${ }^{3}$ See http://www.pcr.uu.se/research/ucdp/, 30 April 2015.

${ }^{4}$ Violent conflicts are categorised as vertical conflicts referring to insurgency-related, separatist or nonseparatist armed struggles against the State; and horizontal conflicts referring to all conflicts without state engagement such as violent struggles between clans, ethnic groups, rival insurgent factions, political parties and private armed groups or shadow authorities. BCMS identifies the following causes of violent conflicts: political; resource; identity; shadow economy; extra-judicial -- under which SGBV such as domestic violence, rape and sexual harassment are classified; and governance. Single or multiple causes for conflicts are recorded.
} 